\title{
EXPERIMENTAL STUDY ON SEISMIC BEHAVIOR OF CLUSTER REINFORCED PRECAST CONCRETE COLUMNS WITH GROUTING-ANCHOR CONNECTIONS
}

\author{
L.H. Xu ${ }^{1}$, Q.L. Wang ${ }^{1}$, M. Yu ${ }^{1 *}$, Y. Chi ${ }^{1, *}$, B. Yang ${ }^{1}$, M. Liu ${ }^{2}$, J.Q. Ye ${ }^{1,3}$ \\ 1. School of Civil Engineering, Wuhan University, China; \\ 2. School of Civil Engineering, Shenyang Jianzhu University, China \\ 3. Department of Engineering, Lancaster University, Lancaster, LA1 4YR. UK
}

\begin{abstract}
The prefabricated residential buildings have become one of the most dominating construction methods in the modern construction industry. The seismic behavior of prefabricated components is crucial in the limit state design of the precast structure. This paper investigates the seismic behavior of a new type precast concrete columns that have clustered steel reinforcement with grouting connection. Quasi-static tests are carried out on three cast-in-situ columns and seven precast columns. Axial compression ratio, lap length and lap space are the main variables considered. The failure process, hysteresis curve, skeleton curve, stiffness degradation, displacement ductility and energy dissipation are elaborated. The experimental results show that the precast columns with the cluster reinforcement have similar seismic behavior to the cast-in-situ columns. Reducing the axial pressure can improve the ductility and energy consumption performance of the cluster reinforced columns, and exert its ductility to improve its seismic performance. During the assembly, a moderate increase in lap length can improve the seismic behavior of precast columns, while the lap space has an insignificant effect on the seismic behavior which indicates that the lap space is not an important factor during construction. The research outcome can serve as a reference for further development and application of precast structures.
\end{abstract}

Keywords: Precast concrete column; cluster reinforcement; Grouting-anchor connection; Seismic behavior; Quasi-static test

\section{INTRODUCTION}

Since the 21 st century, fabricated structures have been widely used in many countries for the advantages of standardization of the design, industrialization of the production, and informationization of the construction process. At present, the main types of fabricated structures are frame structure, shear wall structure and frame shear structure.

For the fabricated frame structure, the key issue of design is the way how the precast components are connected. From the 1890 s, extensive research work has been devoted to uncovering the different types of connection. Ersoy and Tugrul (1993); Hassane et al (2009) have studied the dry-type connection, such as bolted joint (Fig. 1a), welded plate connection (Fig. 1b). Vasconez et al

*Corresponding author: Email: ceyumin@,whu.edu.cn; yin.chi@,whu.edu.cn 
(1998); Zhang (2009); Li (2013); Wang (2013) have done experiments on wet-type connection, such as connection with the slurry anchor (Fig. 1c) and the grouting sleeve (Fig. 1d). But with the increase of building height in recent years, dry-type connection gradually fails to meet the design requirements. Moreover, when the reinforcement arrangement is complex, it is difficult to assemble on construction site and the cost is also high by using the wet-type connection.

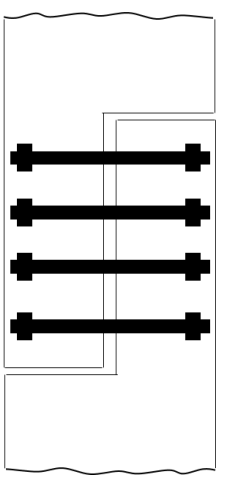

(a) Bolted connection

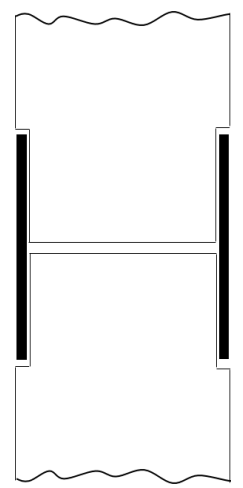

(b) Welded plate

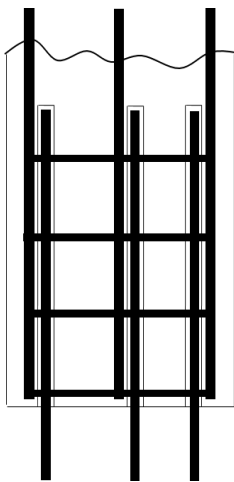

(c) Slurry anchor

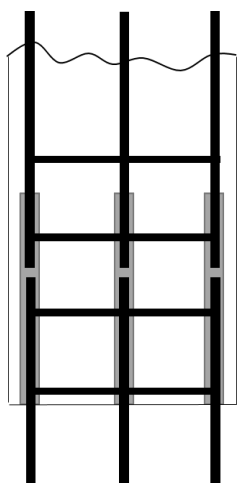

(d) Grouting sleeve

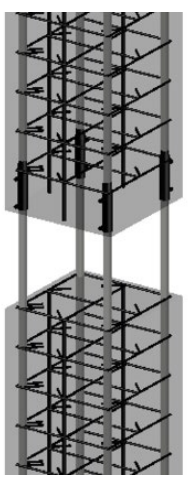

(e) Large-diameter reinforcement

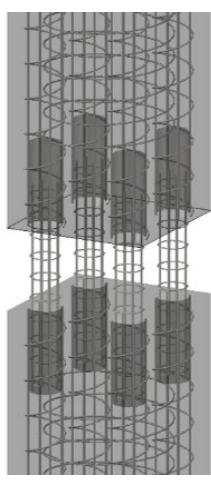

(f) Cluster reinforcement

Figure 1: Different types of connection

To solve this problem, some researchers have proposed the concept of efficient reinforcement to simplify the arrangement and connection of longitudinal reinforcing steel bar. In recent years, Yin et al (2016); Wang (2013) put forward a type of prefabricated columns equipped with large-space and large-diameter high-strength reinforcement (Fig.1e). The results show that the columns have good ductility and energy consumption performance. At present, a new type of prefabricated columns with cluster reinforcement have been proposed by Pei (2017); Liang (2018), which combined the spiral stirrup with grouting-anchor connection (Fig.1f). The cluster reinforced precast concrete column refers to the rebar arranged around the column at the four corner of the column to reduce the number of connections between the vertical bars. However, the seismic behavior of this type of column has not been studied yet.

In order to study the seismic performance of precast columns with cluster reinforcement, quasi-static tests of ten columns are carried out with considering the influence of axial compression ratios, lap lengths and lap spaces. The failure mode, hysteresis performance and energy dissipation et al of cast-in-situ and precast columns are discussed. This study provides experimental data for the application and further research of this type of precast column.

\section{EXPERIMENTAL PROGRAM}

\subsection{Description of the specimens}

From the experiments of Xie and Chen (1998); Lv et al. (2009); Fan (2012), the axial compression ratio is a main factor in the study of seismic behavior. And according to the reinforcement form and connection method, this test considered three influential factors, including axial compression ratio, lap length and lap space (the distance between the outer surface of the longitudinal bars and the 
reserved bars). The length of column is about half height of a layer in high-rise buildings. A total of 7 precast specimens and 3 cast-in-situ full-scale column specimens were designed, respectively numbered as ZP-1 ZP-7 and XJ-1 XJ-3. The specimen designs are shown in Table 1.

Table 1: Main parameter

\begin{tabular}{ccccc}
\hline Number & Lap length $/ \mathrm{mm}$ & Lap space $/ \mathrm{mm}$ & Axial compression ratio & Axial force $/ \mathrm{kN}$ \\
\hline ZP-1 & 420 & 20 & $0.4(0.31)$ & 1200 \\
ZP-2 & 420 & 20 & $0.6(0.46)$ & 1800 \\
ZP-3 & 420 & 20 & $0.8(0.62)$ & 2400 \\
ZP-4 & 250 & 20 & $0.6(0.46)$ & 1800 \\
ZP-5 & 560 & 20 & $0.6(0.46)$ & 1800 \\
ZP-6 & 420 & 30 & $0.6(0.46)$ & 1800 \\
ZP-7 & 420 & 10 & $0.6(0.46)$ & 1800 \\
XJ-1 & -- & -- & $0.4(0.31)$ & 1200 \\
XJ-2 & -- & -- & $0.6(0.46)$ & 1800 \\
XJ-3 & -- & -- & $0.8(0.62)$ & 2400 \\
\hline
\end{tabular}

Note: The former axial compression ratio in the table is the design value; the latter is the actual value.

Each specimen consists of a $400 \mathrm{~mm} \times 400 \mathrm{~mm} \times 1700 \mathrm{~mm}$ column and a $1400 \mathrm{~mm} \times 1400 \mathrm{~mm} \times 600 \mathrm{~mm}$ base. The upper column reinforcement adopts the form of cluster reinforcement, and the connection of the precast column adopts the form of grouting-anchor connection. The concrete is made of C40 commercial concrete, and the longitudinal bars, stirrups in the column and base reinforcement are all made of HRB400 reinforcement, with diameter of $14 \mathrm{~mm}, 8 \mathrm{~mm}$ and $18 \mathrm{~mm}$ respectively. The detailed design of the specimens are shown in Figure 2.

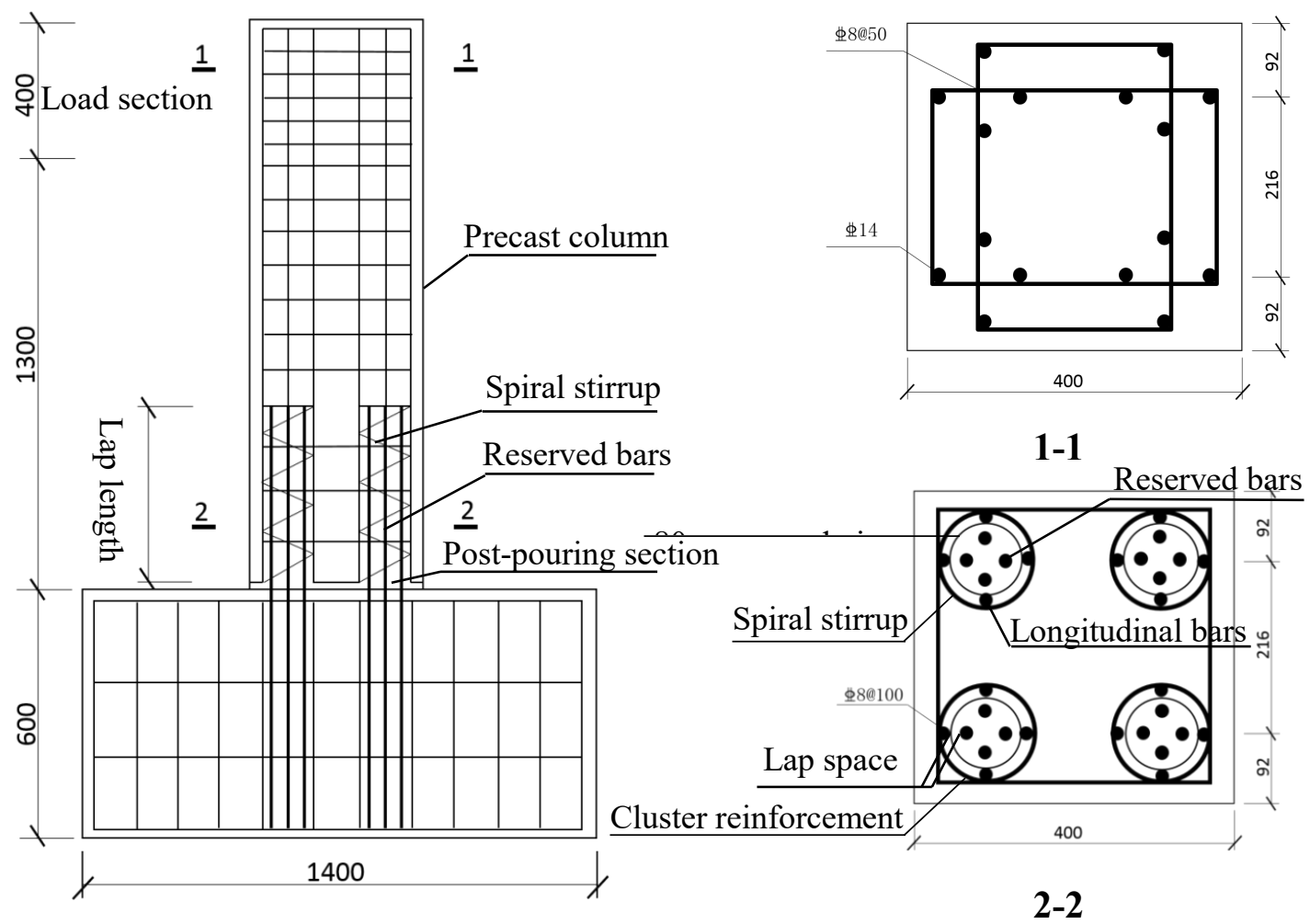

(a) The size and reinforcement of the precast specimen 

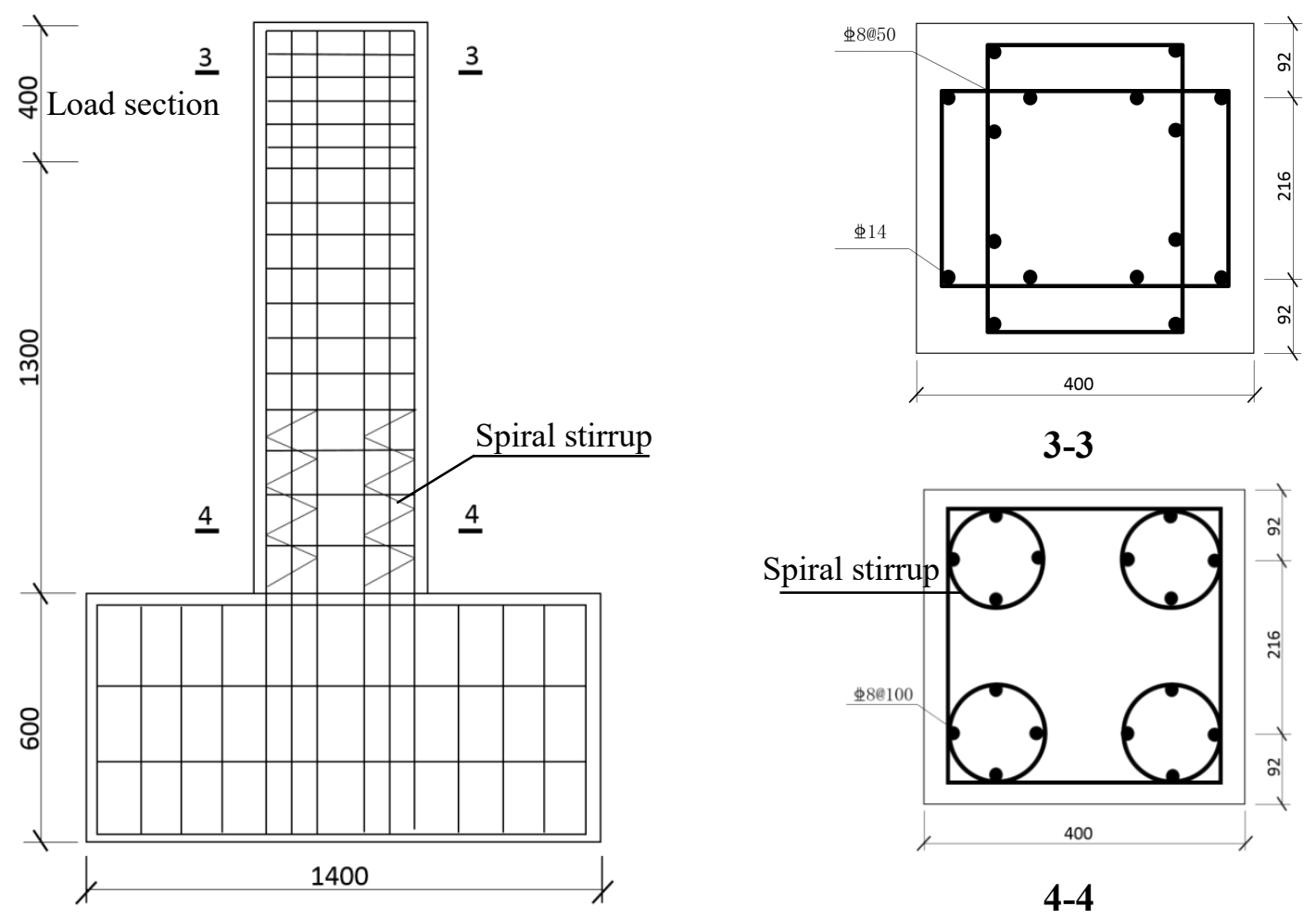

3-3

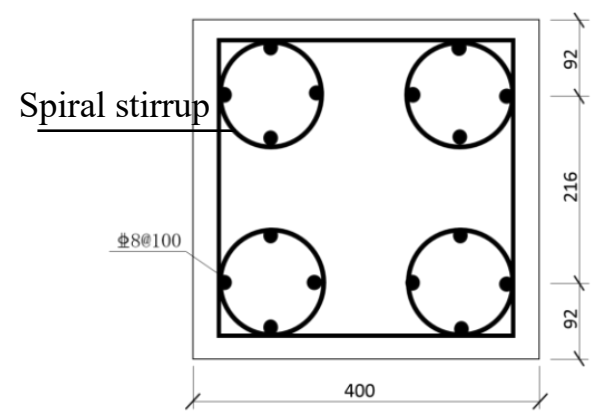

4-4

(b) The size and reinforcement of the cast-in-situ specimen

Figure 2: The size and reinforcement of the specimen

\subsection{Specimen preparation}

The steel cages are tied according to the design of the specimens. The upper columns are equipped with four bundles of 4\$14 longitudinal steel bars and $\$ 8 @ 100$ stirrups, and the stirrups are encrypted in the loading section at the upper end of the column. For precast specimens, a post-pouring hole with a diameter of $80 \mathrm{~mm}$ is reserved by using bellows in the lap length, and two grouting holes are reserved by using a small steel tube with a diameter of $20 \mathrm{~mm}$ at the upper and lower ends of the post-pouring hole. The steel bundles with the same diameter as the longitudinal bars are reserved in the corresponding position according to the lap space. After the lashing work is completed, works on formwork support, concrete pouring are carried out.

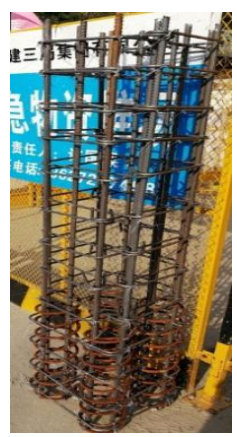

(a) Reinforcement cage

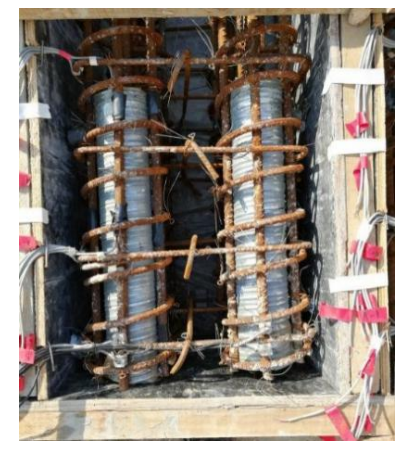

(b) Joint

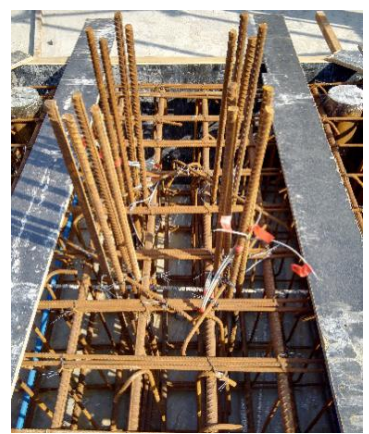

(c) Base with reserved bars

Figure 3: Production process 


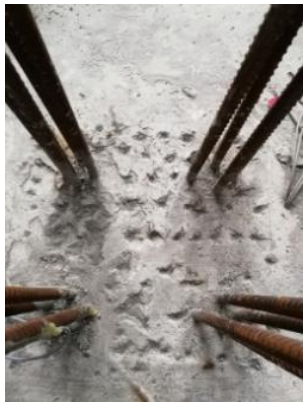

(a) Chiseling

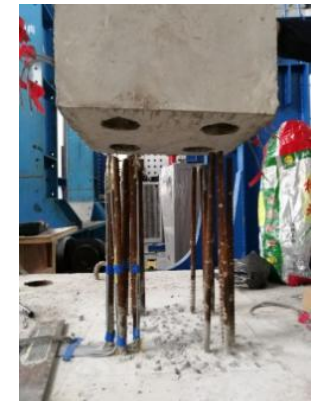

(b) Hoisting

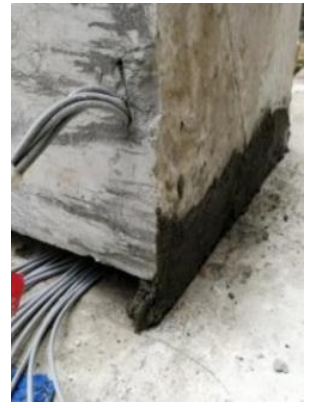

(c) Sealing edge

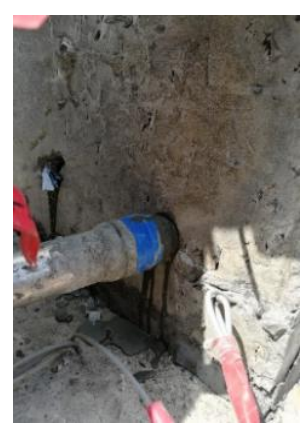

(d) Grouting

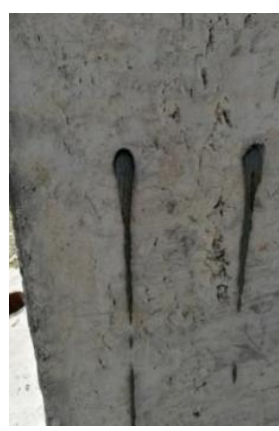

(e) Overflow

Figure 4 : Assembly process

After pouring, the base and precast columns are maintained under standard curing conditions for 28 days, and then the base and column are assembled. In order to ensure sufficient contact between the precast column and the base in the post-grouting, the chiseling is performed in the lap joint area of the base, as shown in Fig. 4a. The reserved steel bundles are inserted into the reserved hole of the column, and $2 \mathrm{~cm}$ gap is reserved behind the lap joint which is then sealed with high-strength slurry, as shown in Figs. 4b and 4c. Then grouting machine is used for grouting from the lower grouting hole until all the upper grouting holes overflow, as shown in Figs. $4 \mathrm{~d}$ and $4 \mathrm{e}$. When the overflow phenomenon occurs, the grouting is completed, and the upper and lower grouting holes are blocked and cured for 28 days.

In the concrete pouring and grouting process, the concrete and grouting cubic test blocks are prepared and maintained under the same conditions, then the compressive strength is measured and the average value of each specimen is taken as the test value. This test uses $\mathrm{C} 40$ commercial concrete, the measured cubic compressive strength $f_{c u, k}$ is $36.6 \mathrm{MPa}$, and the axial compressive strength is $f_{c k}=0.88 \times 0.76 \times 36.6=24.5 \mathrm{MPa}$. The grouting material is made of high-strength and non-shrinkage grout, and its compressive strength is $92.3 \mathrm{MPa}$. The steel bars used in the test are all HRB400 bars. Through the steel bar tensile test, the yield strength $f_{y}$ of the longitudinal bars is $556.8 \mathrm{MPa}$, the ultimate strength $f_{u}$ is $630.1 \mathrm{MPa}$. The yield strength $f_{y}$ of the ordinary stirrups is $390.1 \mathrm{MPa}$, and the ultimate strength $f_{u}$ is $524.2 \mathrm{MPa}$. The yield strength $f_{y}$ of the spiral stirrup is 423.5 MPa, and the ultimate strength $f_{u}$ is $576.3 \mathrm{MPa}$.

\subsection{Loading and measurement}

The loading device is shown in Figure 5. The bottom end of the specimen is fixed to the floor. The vertical axial force is loaded by the jack. The jack and the rigid beam are connected by the sliding bearing to reduce the horizontal friction. The horizontal load is applied by the servo actuator having a loading capacity of 60 tons.

During the loading, a predetermined load is first applied and kept as a constant. A horizontal load is applied then at the top of the column. The horizontal loading process is divided into two stages. In the first stage, cyclic load is applied to the columns. The amplitude of the load starts from 50KN that is increased by $50 \mathrm{KN}$ after a cycle is completed until the steel yields. The displacement at yielding is recorded and serves as loading step in the second stage where loading is controlled by displacement. Three cycles of loading are performed for each of the displacement step until the 
horizontal load drops to $85 \%$ of the peak load or the specimen has been severely damaged and the loading is then terminated.

During the test, the displacement meters are arranged at the loading center, 1/2 column height, $1 / 4$ column height and the base to measure the horizontal displacement of the column at different heights. Within the lap length, the strain gauges are arranged on the longitudinal bars, reserved bars, spiral stirrups and stirrups to detect the strain changes of each bar during the loading process.

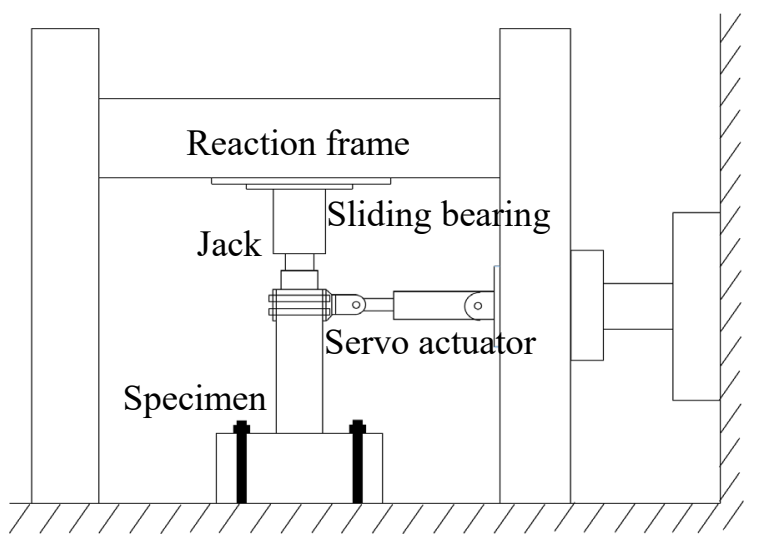

(a) Loading diagram

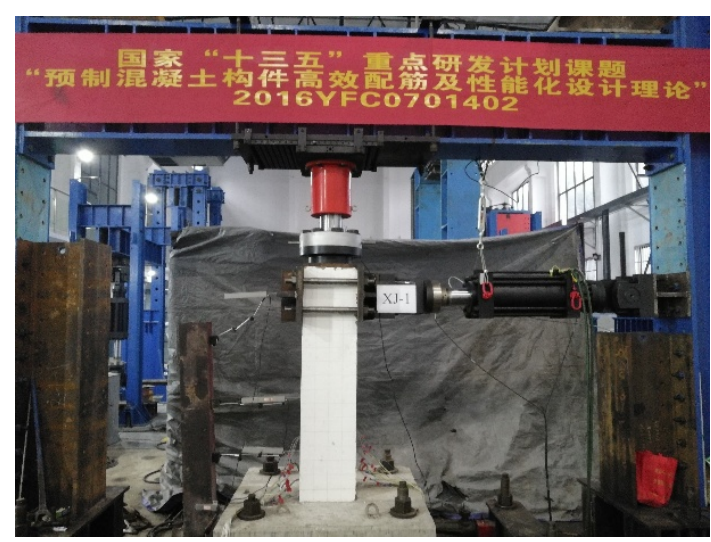

(b) Test on site

Figure 5: Loading device

\section{EXPERIMENTAL RESULTS}

\subsection{Experimental observations}

The typical failure progress of the cast-in-situ specimen (XJ-2) and precast specimen (ZP-2) are shown in Figure 6 and Figure 7.

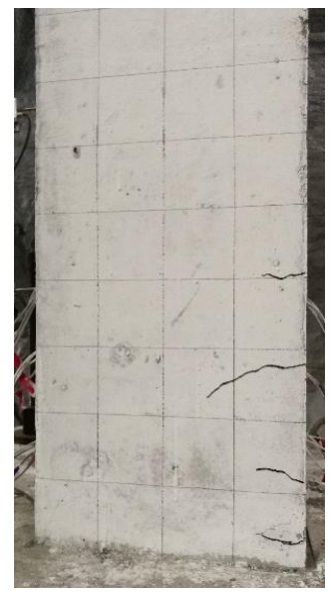

(a) Initial crack

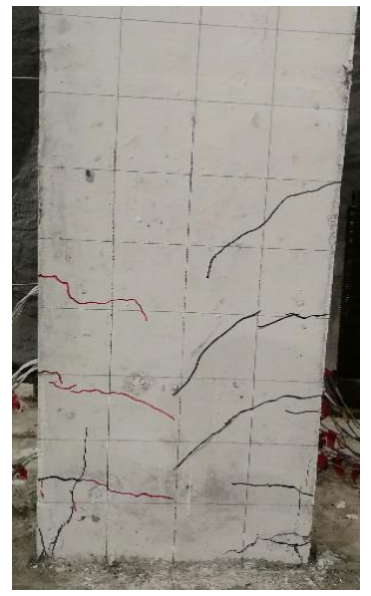

(b) Crack development

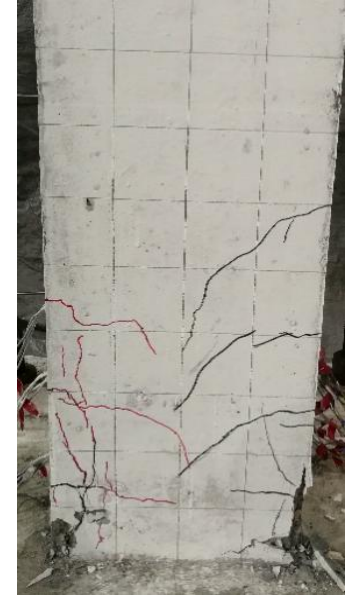

(c) Vertical crack

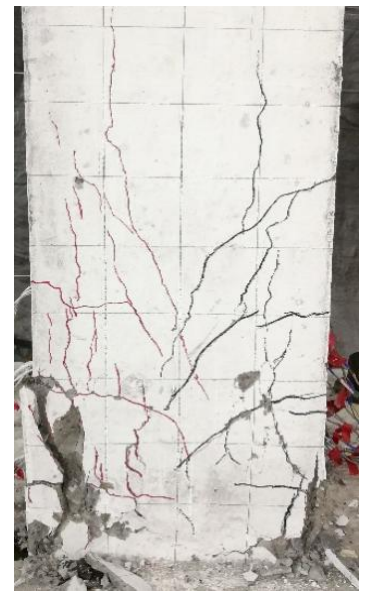

(d) Concrete spalling

Figure 6: Destruction process of cast-in-situ specimen (XJ-2) 


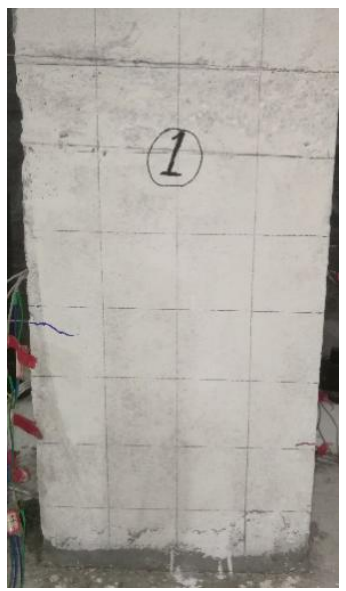

(a) Initial crack

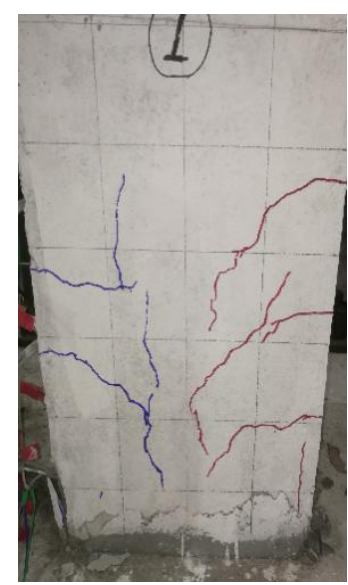

(b) Crack development

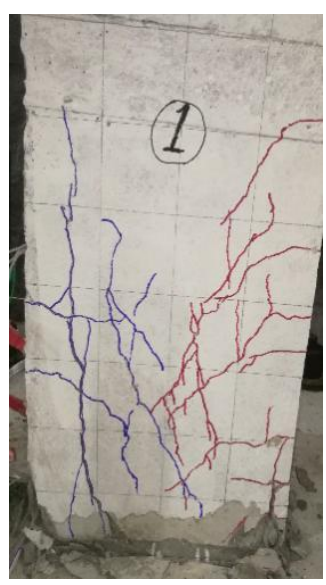

(c) Vertical crack

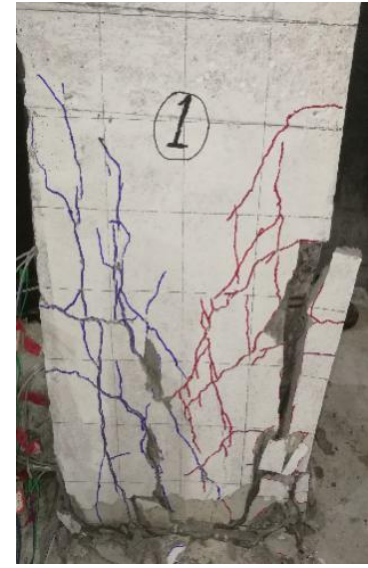

(d) Concrete spalling

Figure 7: Destruction process of precast specimen (ZP-2)

In order to facilitate the description of the failure process of the test, the sides perpendicular to the horizontal loading direction are defined as the left and right sides, and the sides parallel to the loading direction are the front and back sides. The destruction process are described as follows:

(1) For the cast-in-situ specimens, before the initial crack showed up, it is in the elastic stage, and the load-displacement curve is linear. When loading to about $200 \mathrm{kN}$, initial horizontal cracks appear on the front and back of the specimen, as shown in Fig. 6a. As the displacement increases, the cracks became inclined and wider, as shown in Fig. 6b. More inclined cracks are found near the bottom. On the left and right sides of the column, there are horizontal cracks running through the width of the sides. When the displacement continues to increase, the longitudinal reinforcement at the bottom of the column yields, and the longitudinal cracks begin to appear at the column foot, as shown in Fig. 6c. Longitudinal cracks continue to develop until the concrete is peeled off, and part of the longitudinal steel bars are exposed, as shown in Fig. $6 \mathrm{~d}$. The bearing capacity of the specimen drops to about $85 \%$ of the peak load, and the specimen reaches the failure state.

(2) For the precast specimens, before the cracking, it is in the linear elastic working stage. When loading to about $200 \mathrm{kN}$, the initial cracks of the specimen appear at the joint of the post-casting section, and the load-displacement curve begins to deviate from the straight line, as shown in Fig. 7a. With the continuous loading, the cracks appear and develop in the range of the lap length, which are more obvious than those in the post-pouring section, as shown in Fig. 7b. With the widening of the crack, some vertical cracks appear at the feet of the columns and gradually extend upward, as shown in Fig. 7c. After that, with the increase of displacement, the concrete began to crush and fall off, and the load bearing capacity of the specimen decreased until about $85 \%$, and the specimen reaches the state of failure, as shown in Fig. $7 \mathrm{~d}$.

By comparing the failure progress, the following differences can be observed: the initial crack location of the cast-in-situ column is within $1 / 3$ of the column feet, while for the precast type, due to the lack of cohesive force in the post-pouring section, the cracks initially appear at the joint of the post-pouring section. The final cracks of the cast-in-situ columns are developed by the first batch of cracks, while the cracks in the post-pouring section of the precast columns have no obvious changes during the later loading process, and they are dominated by the cracks of the column. 


\subsection{Hysteresis curves}

The hysteresis curves of each specimen are shown in Figure 8. The figure shows that the shape, size and evolution process of the hysteretic curves of the precast specimens are basically similar to those of the cast-in-situ specimens. The hysteretic loops are all relatively plump, and are basically in the shape of a spindle. With the increase in the displacement, the plastic hinge at the bottom of the column is formed and developed. The area surrounded by each hysteresis loop is gradually increased, and the energy consumption capacity is continuously increased. When the horizontal force reaches the ultimate load, the horizontal load begins to decrease gradually, and the stiffness degrades obviously, thus the hysteresis loop moves towards the displacement axis gradually, resulting in different degrees of pinching.

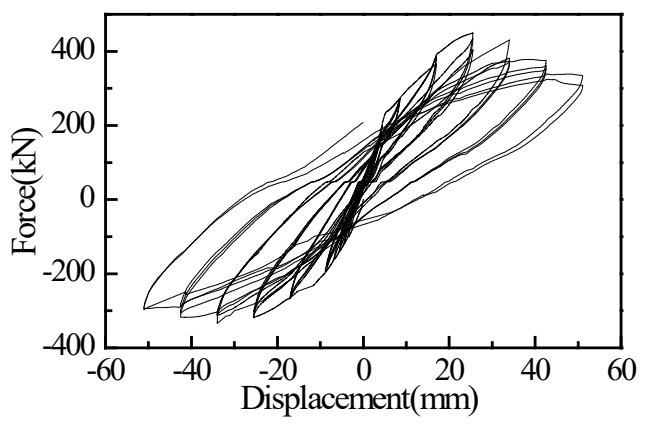

(a)XJ-1

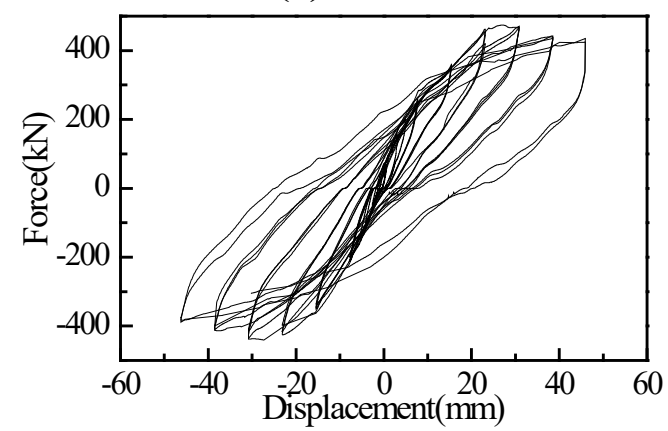

(c) $\mathrm{XJ}-3$

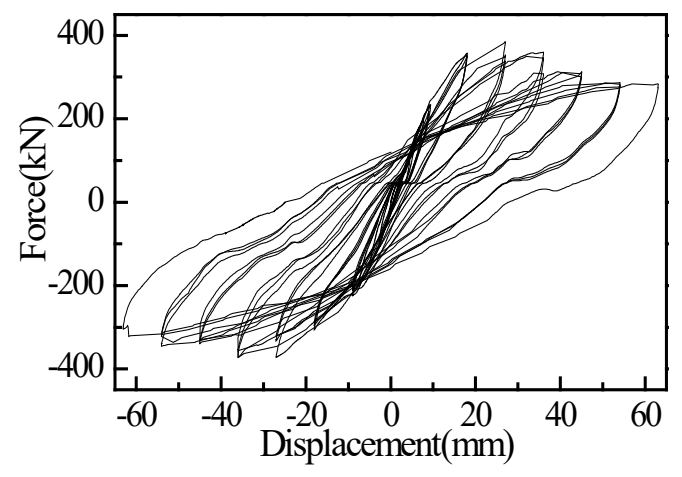

(e) ZP-2

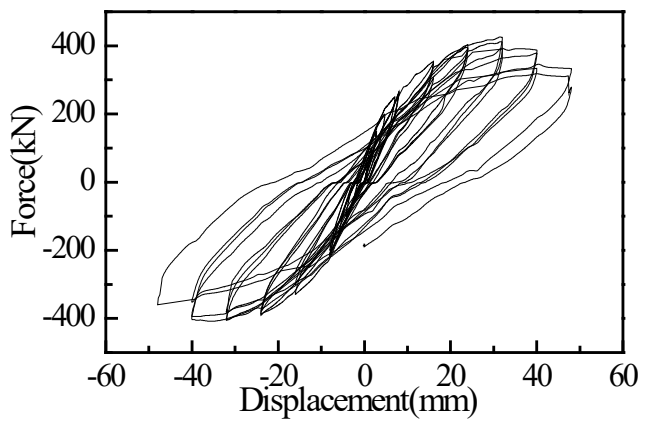

(b) XJ-2

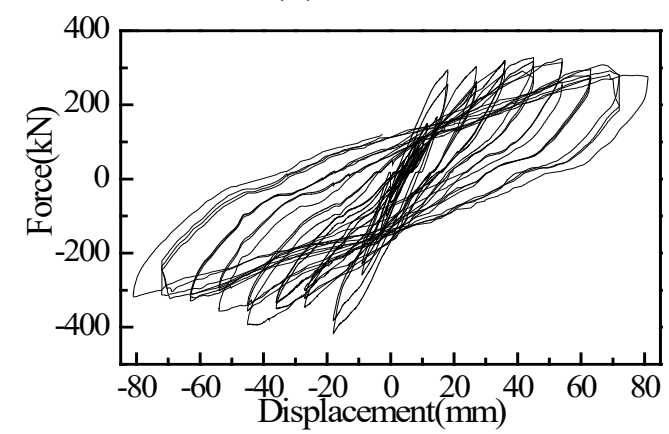

(d) ZP-1

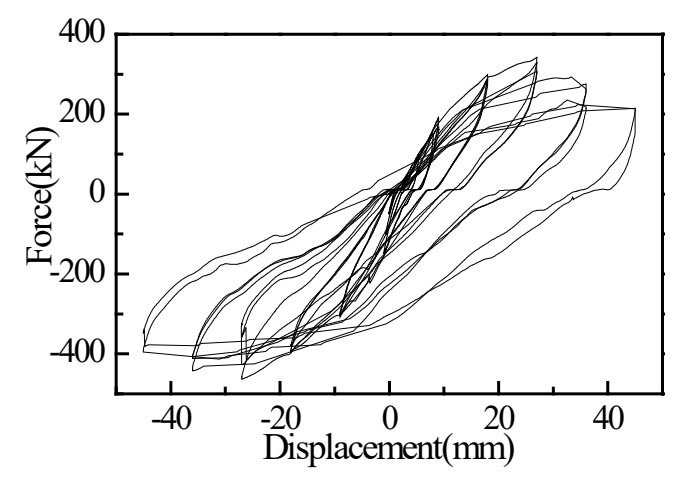

(f) ZP-3 


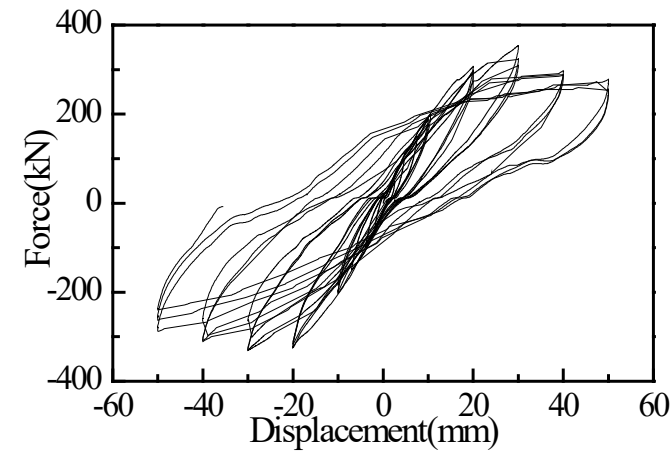

(g) ZP-4

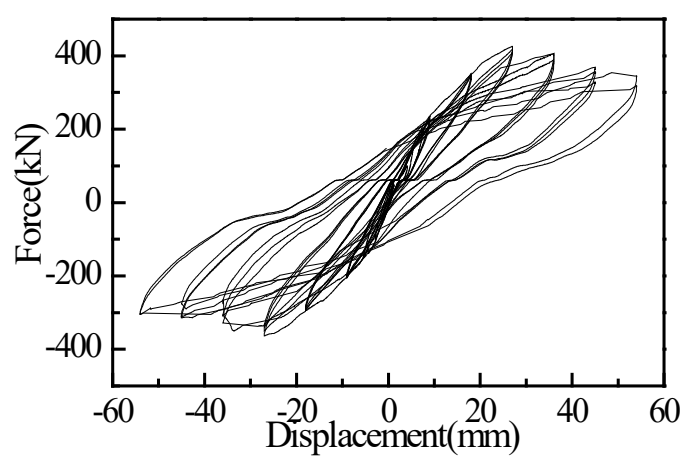

(i) ZP-6

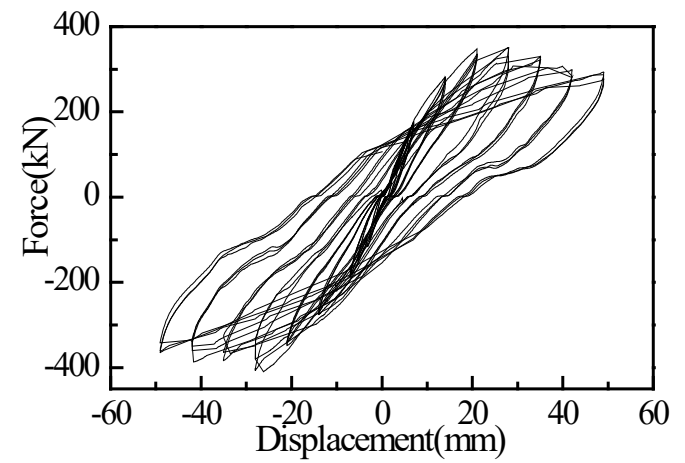

(h) ZP-5

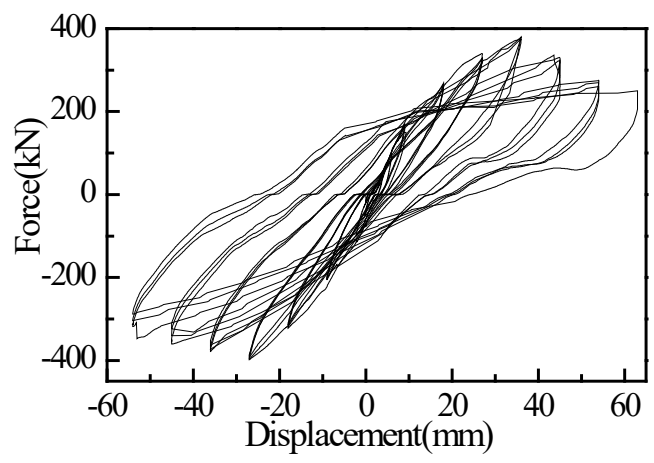

(j) ZP-7

Figure 8: Hysteresis curves

\section{TEST RESULTS ANALYSIS}

\subsection{Skeleton curves}

The skeleton curves of each specimen are shown in Figure 9. It is showed that at the initial loading stage of each specimen, the skeleton curves are basically coincident with each other, indicating that the initial stiffness of the precast column and the cast-in-situ column specimens are basically the same. Under the same axial compression ratio, the horizontal bearing capacity of the precast specimen is decreased by $4.5 \%$ and the ultimate displacement is increased by $12.5 \%$ compared with the cast-in-situ specimen, as shown in Fig. 9a. As the axial compression ratio increases, the bearing capacity decreases faster and the strength deteriorates rapidly, as shown in Fig. 9b. When the lap length increases from $250 \mathrm{~mm}$ to $420 \mathrm{~mm}$, then to $560 \mathrm{~mm}$, the ultimate bearing capacities increase obviously first, and then fluctuates slightly, as shown in Fig. 9c. Under different lap space, the bearing capacity and ultimate displacement of the specimens are not significantly different, indicating that the factor has little effect on the skeleton curves, as shown in Fig. 9d. 


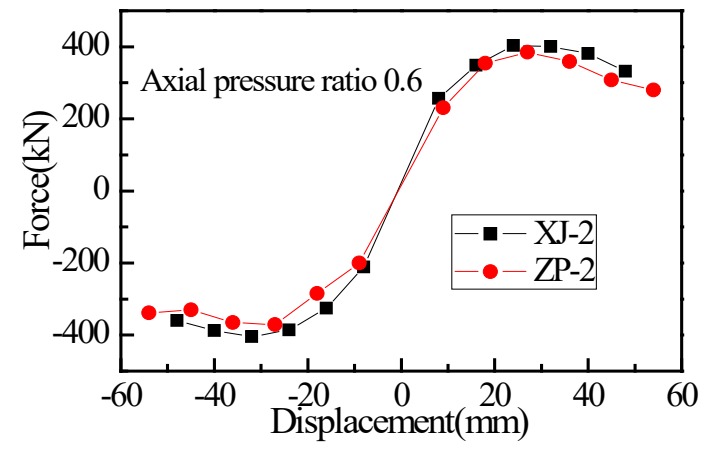

(a) Cast-in-situ and precast columns

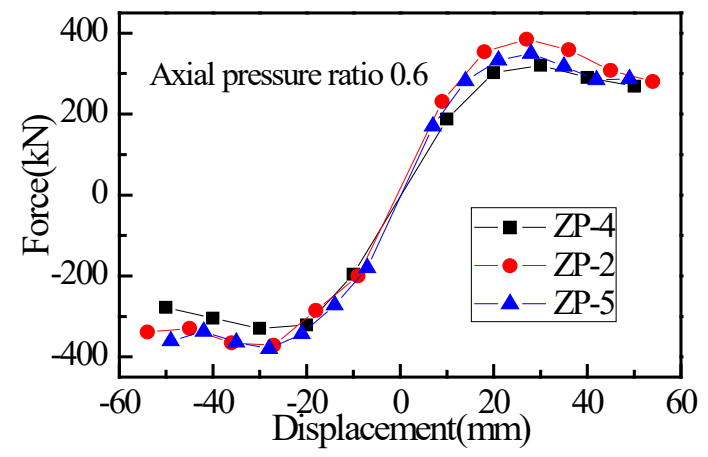

(c) Different lap length

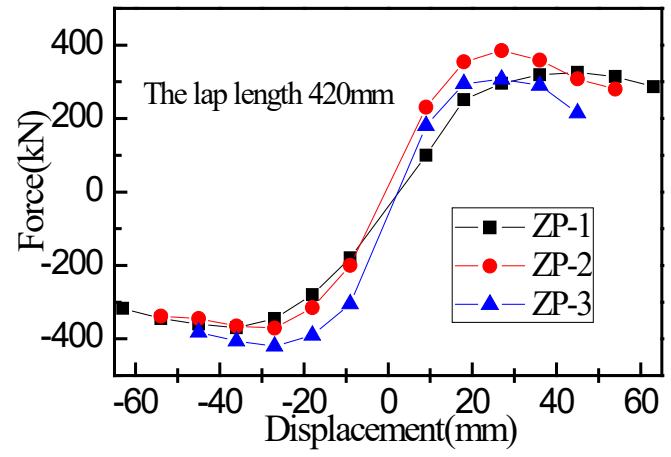

(b) Different axial pressure ratio

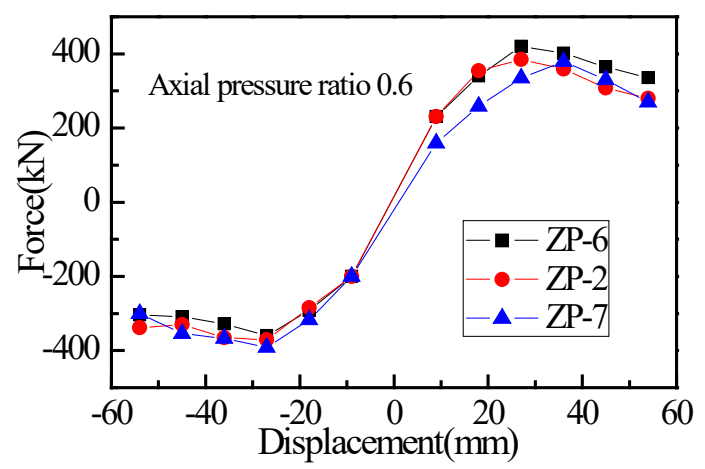

(d) Different lap space

Figure 9: Skeleton curves

\subsection{Displacement ductility}

Based on the skeleton curves, the yield displacement and the ultimate displacement corresponding to $85 \%$ of the maximum load in the loading process of each specimen are calculated, and then $R_{y}$ (the yield displacement angles) and $R_{u}$ (the ultimate displacement angles) of the specimens are calculated by the yield and ultimate displacement. The yield displacement angle, ultimate displacement angle and displacement ductility coefficient of each specimen are shown in Table 2.

Table 2: Displacement ductility coefficient calculation

\begin{tabular}{|c|c|c|c|c|c|c|c|c|c|}
\hline \multirow{2}{*}{ Number } & \multicolumn{3}{|c|}{ Positive } & \multicolumn{3}{|c|}{ Negative } & \multirow{2}{*}{$R_{y}$} & \multirow{2}{*}{$R_{u}$} & \multirow{2}{*}{$\mu$} \\
\hline & $\triangle_{u}^{+} / \mathrm{mm}$ & $\triangle_{y}^{+} / \mathrm{mm}$ & $\mu^{+}$ & $\triangle_{u}^{-} / \mathrm{mm}$ & $\Delta_{y}^{-} / \mathrm{mm}$ & $\mu^{-}$ & & & \\
\hline ZP-1 & 78.51 & 20.41 & 3.85 & -58.5 & -19.07 & 3.07 & $1 / 76.0$ & $1 / 21.9$ & 3.46 \\
\hline $\mathrm{ZP}-2$ & 42.05 & 17.20 & 2.47 & -58.63 & -20.51 & 2.86 & $1 / 79.5$ & $1 / 29.8$ & 2.67 \\
\hline ZP-3 & 34.5 & 17.50 & 1.97 & -42.57 & -19.43 & 2.19 & $1 / 81.2$ & $1 / 38.9$ & 2.08 \\
\hline ZP-4 & 40.15 & 22.25 & 1.80 & -52.07 & -18.53 & 2.81 & $1 / 73.6$ & $1 / 32.5$ & 2.31 \\
\hline ZP-5 & 53.21 & 16.57 & 3.21 & -59.7 & -23.67 & 2.52 & $1 / 74.6$ & $1 / 26.6$ & 2.87 \\
\hline ZP-6 & 48.85 & 19.72 & 2.48 & -51.10 & -20.05 & 2.55 & $1 / 75.4$ & $1 / 30.0$ & 2.52 \\
\hline ZP-7 & 46.11 & 16.36 & 2.81 & -48.42 & -21.6 & 2.24 & $1 / 79.0$ & $1 / 31.7$ & 2.49 \\
\hline XJ-1 & 51.22 & 18.23 & 2.81 & -58.8 & -17.82 & 3.30 & $1 / 83.2$ & $1 / 27.3$ & 3.06 \\
\hline $\mathrm{XJ}-2$ & 44.23 & 16.91 & 2.62 & -46.46 & -17.65 & 2.63 & $1 / 86.8$ & $1 / 33.1$ & 2.63 \\
\hline XJ-3 & 42.7 & 20.26 & 2.11 & -55.32 & -18.67 & 2.96 & $1 / 77.0$ & $1 / 30.6$ & 2.54 \\
\hline
\end{tabular}


It can be seen from the table that the ultimate displacement angle of each specimen is greater than $1 / 50$, which meets the requirement of China's seismic code that the reinforced concrete frame structure under the rare earthquakes should reach 1/50 allowable limit deformation. With the increase in the axial compression ratio, the yield load and ultimate load of specimens are increased, and the yield displacement and ultimate displacement are decreased, showing a decrease in the displacement ductility coefficient. With the lap length increasing from $250 \mathrm{~mm}$ to $420 \mathrm{~mm}$ and then to $560 \mathrm{~mm}$, the yield displacement and ultimate displacement of the specimen are increased, and the displacement ductility coefficients increases by $15.6 \%$ and $7.5 \%$ respectively, indicating that the impact on the ductility coefficient decrease after the lap length reached a certain length. With the increase of steel space, the displacement ductility coefficient of specimens fluctuates within $7 \%$, indicating that the steel space has little influence on the displacement ductility coefficient.

\subsection{Stiffness degradation and strength degradation}

Under the cyclic loading after yielding, the stiffness of the specimen gradually decreases with the increase in the displacement level, showing the phenomenon of stiffness degradation. The expression of the average stiffness of the specimen under a certain displacement is

$$
K_{\mathrm{m}}=\frac{\sum_{i=1}^{n} p_{j-1}}{n \Delta_{j}}
$$

where, $p_{j-1}$ is the measured value of the maximum cyclic load of the $\mathrm{i}$-th when the displacement is $\Delta_{j}, \Delta_{j}$ is the displacement control value of the $\mathrm{j}$-th load level, and $\mathrm{n}$ is the number of cyclic loading under the same displacement.

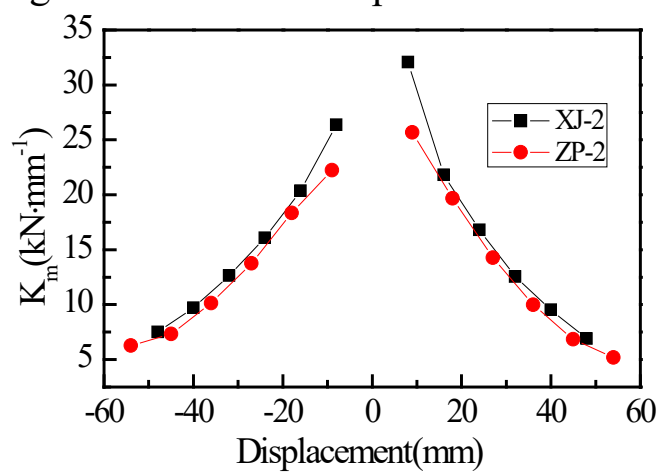

(a) Cast-in-situ and precast columns

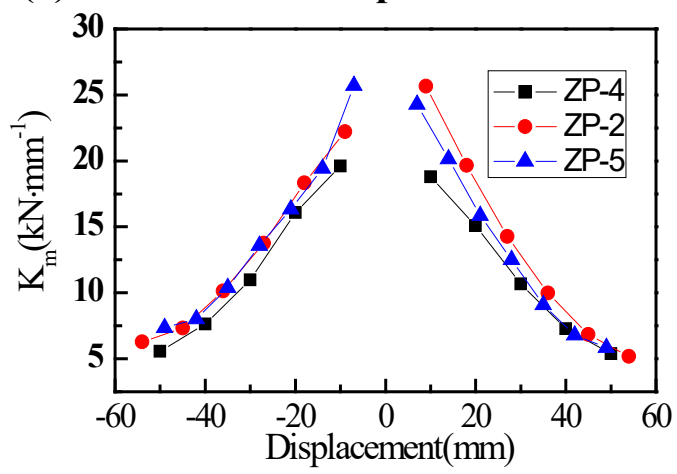

(c) Different lap length

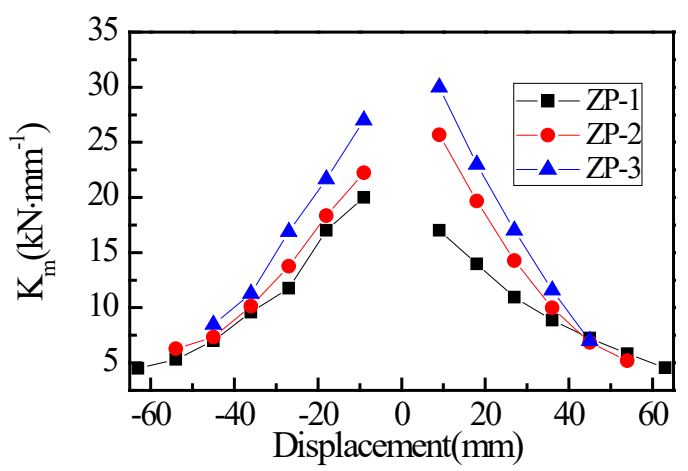

(b) Different axial pressure ratio

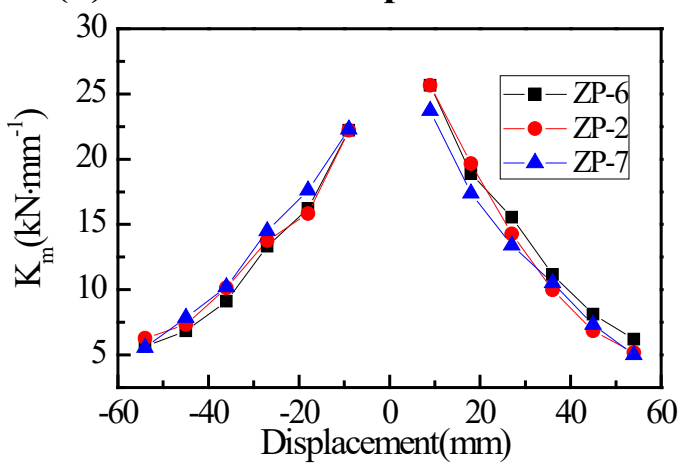

(d) Different lap space

Figure 10: Stiffness degradation 
According to the above formula, the changes of the tangential stiffness of each specimen with the increase of the displacement level are shown in Figure 10. The Fig. 10a shows that the stiffness of the cast-in-situ and precast columns are almost the same and the two columns have similar rate of stiffness degradation as the load increase. With the increase of axial pressure ratio, the initial stiffness of the specimen gradually increases, but the decreasing slope also gradually increases, indicating that the stiffness degradation is accelerated, as shown in Fig. 10b. As the lap length increases from $250 \mathrm{~mm}$ to $420 \mathrm{~mm}$, and then to $560 \mathrm{~mm}$, the stiffness of the specimen is increased first, but keep unchanged later, as shown in Fig. 10c Regardless of the change in lap space, the difference in stiffness degradation of the specimens is small, as shown in Fig. 10d.

\subsection{Energy consumption}

The energy consumption capacity of reinforced concrete specimens is evaluated by the equivalent viscous damping coefficient and accumulated energy consumption. The calculation formulas of the equivalent viscous damping coefficient and accumulated energy consumption are shown in equation (2) and (3).

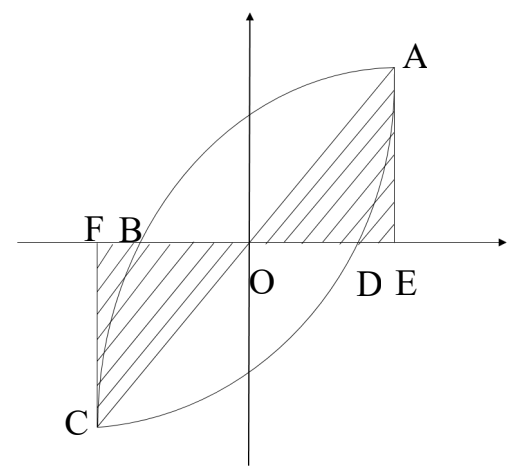

The equivalent viscous damping coefficient:

$$
\xi_{e}=\frac{S_{A B C D}}{2 \pi \times\left(S_{\triangle O F C}+S_{\triangle O E A}\right)}
$$

The accumulated energy consumption:

$$
E=\int_{A B C D A} d l
$$

\section{Figure 11: The calculation diagram}

The energy consumption capacities of specimens are shown in Figure 12. By analyzing the variation pattern of equivalent viscous damping coefficient and accumulated energy consumption in the figure, it shows that the equivalent viscous damping coefficient and energy consumption value of each specimen show an increasing trend with the increase in the displacement level. Under the same axial pressure ratio of 0.6 and at the same displacement level, the equivalent viscous damping coefficient of the precast specimen is lower than that of the cast-in-situ specimen, and the cumulative energy consumption difference is small, as shown in Fig. 12a. As the axial compression ratio increases, the area surrounded by the hysteresis loop of the specimen gradually increases, and the energy consumption capacity increases, as shown in Fig. 12b. When increasing the lap length from $250 \mathrm{~mm}$ to $420 \mathrm{~mm}$, then to $560 \mathrm{~mm}$, the growth rate of accumulated energy consumption shows a trend from rapid to gentle, as shown in Fig. 12c. The change of the lap space has little effect on the cumulative energy consumption, which means the energy consumption of the specimens is not significantly related to the lap space, as shown in Fig. 12d. 

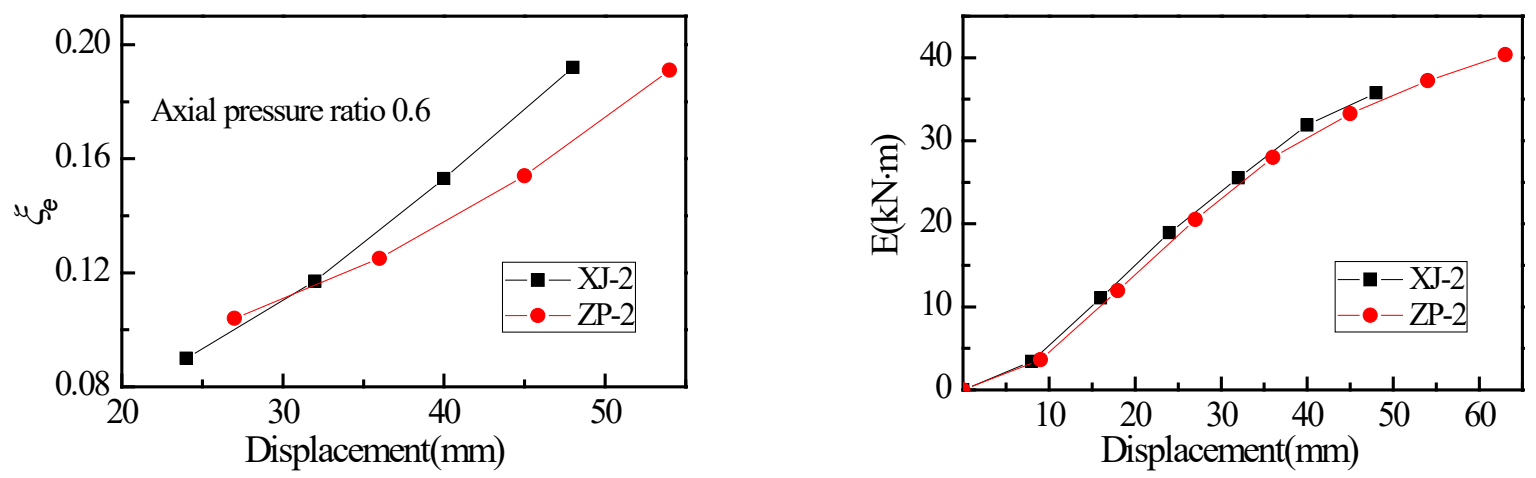

(a) Cast-in-situ and precast columns
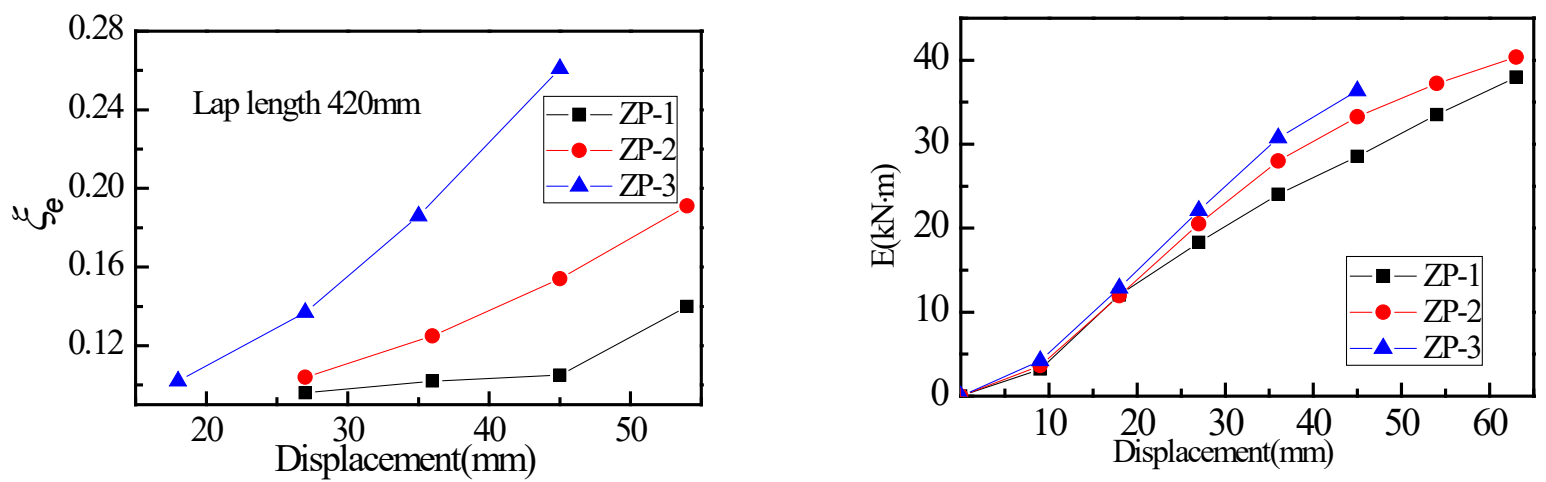

(b) Different axial pressure ratio
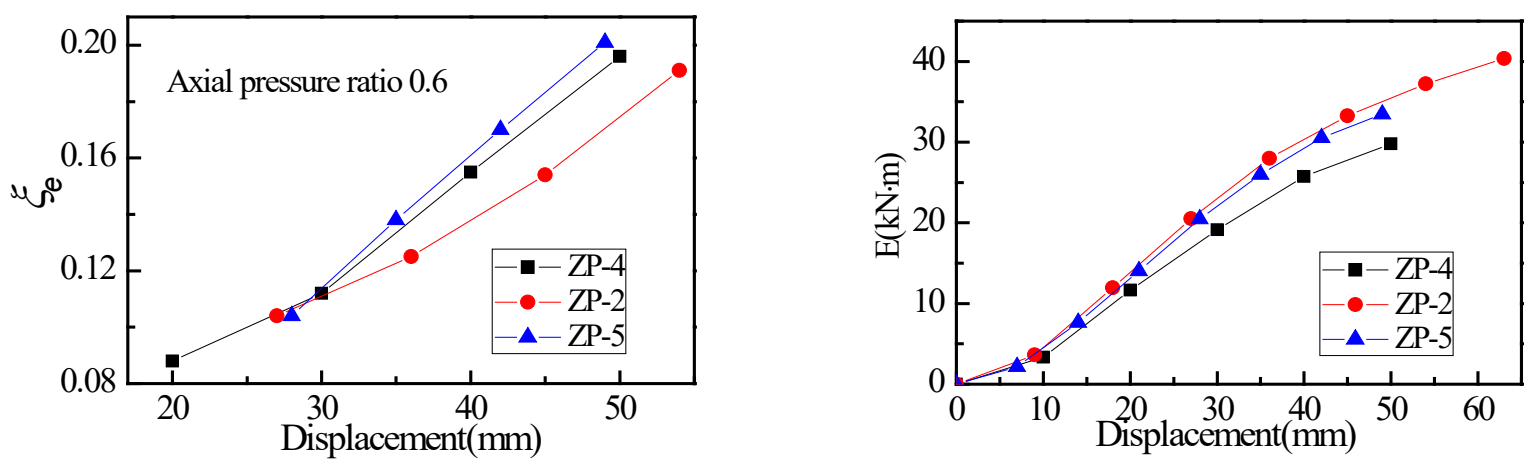

(c) Different lap length
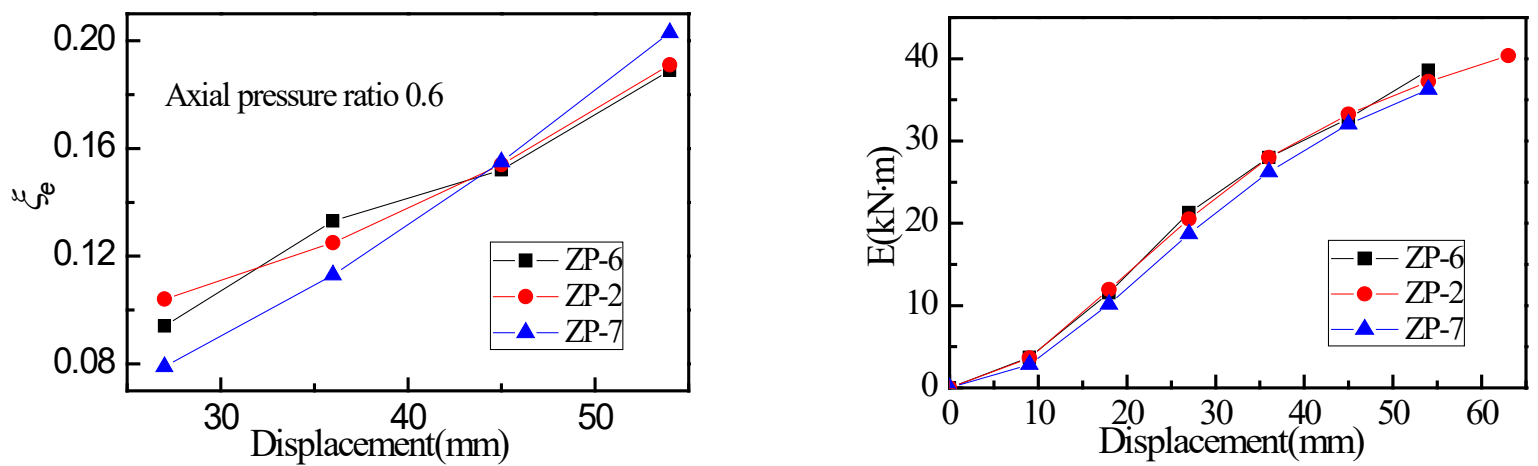

(d) Different lap space

Figure 12: Equivalent viscous damping coefficient and cumulative energy consumption 


\section{CONCLUSION}

In the form of cluster reinforcement, the seismic behavior of precast columns were tested and compared with the cast-in-situ columns. According to the test results, the following conclusions are drawn:

(1) The precast column with cluster reinforcement has comparable seismic performance with the cast-in-situ column. It is shown the bending failure mode for both of them, and the bearing capacity and energy consumption of the cast-in-situ columns are slightly higher than that of precast columns.

(2) Reducing the axial pressure can improve the ductility and energy consumption performance of the cluster reinforced columns, and exert its ductility to improve its seismic performance. With the increase of axial compression ratio, the bearing capacity of the specimens increase, but its stiffness degradation and strength degradation are gradually accelerated.

(3)An appropriate increase in the lap length can improve the seismic behavior of the precast columns, while an excessive increase of the length has little effect on it. A lap length of 30 times of the diameter of longitudinal reinforcement is recommended to achieve a favorable design.

(4) In the assembly process, different lap space has little effect on the seismic performance of the cluster reinforced precast columns. Therefore, lap space should be designed predominated by satisfying other design.

At present, due to the limited parameters considered in the test, numerical simulations are required in the later stage.

\section{ACKNOWLEDGEMENT}

The authors are grateful for the financial support from the National Key Research and Development Program of China (2016YFC0701402).

\section{REFERENCES}

Alcocer SM, Carranza R, Perez-Navarrete D, et al (2002). Seismic Tests of Beam-to-column Connections In a Precast Concrete Frame. Journal of PCI, 47(3), pp.70-89.

Chen J and Xiao Y(2016). Experimental Study on Seismic Behavior of Precast Concrete Column with Longitudinal Reinforcement Grouting-anchoring Connections. Journal of China Civil Engineering, 49(5), pp. 63-73.

Choi HK, Bae B, Choi YC, et al (2012). Behaviour of precast concrete beam-column connections using steel plate and ECC. Journal of Advanced Science Letters, 14(1), pp.262-268.

Chun-Lin Wang*, Ye Liu* and Li Zhou. Experimental and numerical study on hysteretic behavior of all-steel bamboo-shaped energy dissipaters. Engineering Structures, 165, 38-49, 2018

Chun-Lin Wang*, Ye Liu, Xiaolong Zheng and Jie Wu. Experimental investigation of a precast concrete connection with all-steel bamboo-shaped energy dissipaters. Engineering Structures, 178, 298-308, 2019

Ersoy, U and Tugrul T (1993). Precast Concrete Members With Welded Plate Connections Under Reversed Cyclic Loading. Journal of PCI, 38(4), pp.94-100.

Fan L (2007). Investigation on Seismic Behavior of Jointed Precast Concrete Frame Structure. Master. D. thesis, Tongji University.

Fan P (2012). Experimental Research on Seismic Behavior of Reinforced Concrete Columns with Cross-shaped Section. 
Master. D. thesis, Tianjin University.

GB 50010-2010(2016 Edition) Code for design of concrete structures (2011). Beijing: China Construction Industry Press. (in Chinese)

GB50011-2010(2016 Edition) Code for seismic design of buildings (2010). Beijing: China Construction Industry Press. (in Chinese)

GJ 1-2014 Technical specification for precast concrete structures (2014). Beijing: China Architecture \& Building Press. ( in Chinese)

Jiang QJ (2010). Summary on Development of Assembled Concrete Buildings Both Home and Abroad. Journal of Building Technology, 41(12), pp.1074-1077.

Lu Q (2017). The history and current status of German fabricated buildings. Journal of Residential Industry, 25(2), pp. 78-83.

Li SD (2013). Experimental Study on Seismic Performance of Precast Concrete Columns and Joints. Master. D. thesis, Harbin Institute of Technology.

Liang HW (2018). Experimental Study on Compressive Behavior of Precast Concrete Columns with Cluster Reinforcement. Master. D. thesis, Shenyang Jianzhu University.

Lv XL, Zhang GJ and Chen SL (2009). Research on seismic behavior of full-scale high-strength concrete frame columns with high axial compression ratios. Journal of building structures, 30 (3), pp. 20-26.

Ousalem, H (2009). Seismic performance and flexural stiffness variation of assembled precast high-strength concrete beam jointed at midspan using transverse bolts. Journal of Advanced Concrete Technology, 7(2), pp. 205-216.

Ozturan T, Ozden S and Ertas O (2006). Ductile Connections in Precast Concrete Moment Resisting Frames. Journal of Prestressed Concrete Institute, 51, pp. 66-76.

Pei ZY (2017). Experimental Research and Vertical Connection Method on Precast Reinforced Concrete Column by cluster of steel bars. Master. D. thesis, Shenyang Jianzhu University.

Peng CF, Zheng QZ and Long LB, et al (2016). Experimental Study on Seismic Performance of Precast Columns Connected by UHPC Materials. Journal of Building Construction, 38(12), pp.1711-1713.

Priestley MJN and Macrae GA (1996). Seismic Tests of Precast Beam-to-Column Joint Subassemblages With Unbonded Tendons. Journal of PCI, 41(1), pp.64-81.

Restrepo JI, Park R, and Buchanan AH (1995). Design of Connections of Earthquake Resisting Precast Reinforced Concrete Perimeter Frames. Journal of PCI, 40(4), pp.44-61.

Vasconez RM, Naaman AE and Wight JK (1998). Behavior of HPFRC Connections for Precast Concrete Frames Under Reversed Cyclic Loading. Journal of PCI, 43(6), pp.58-71.

Wang J (2013). Experimental Research on Seismic behavior of Reinforced Concrete Columns assembled by Grout-filled Sleeve and Mechanical Connection. Master. D. thesis, Xi'an University of Architecture And Technology.

Wang XF (2013). Study on Seismic behavior of High Strength Reinforced Concrete Frame Columns. Ph. D. thesis, China Academy of Building Research.

Wu CX, Zhang YF and Zhang C, et al (2015). Study on Seismic Performance of Prefabricated Concrete Beam-column Joint. Journal of Engineering seismic and Reinforcement retrofitting, 37(1), pp. 83-90.

Xie T and Chen YY (1998). Experimental Study on Seismic Performance of High Strength Concrete Columns. Journal of Building Structure (12), pp. 3-6.

Yin XW, Huang XK and Tian CY, et al (2016). Experimental study on seismic performance of reinforced concrete columns with large space and high strength longitudinal reinforcement. Journal of Architecture, 37(8), pp.41-47.

Zhang HS (2009). Experimental study on plug-in filling hole for lap-joint of steel bar of PC concrete structure. Master. D. thesis, Harbin Institute of Technology.

Zhao P (2011). Experimental research on restraint grouting-anchoring overlap-joint of steel bar. Master. D. thesis, Harbin Institute of Technology. 
Zhao B, Lv XL and Liu HF (2004). Experimental study on seismic performance of precast concrete beam-column subassemblage with cast-in-situ monolithic joint. Journal of Architectural Structure, 25(6), pp. 22-28.

Zhao Y, Li R and Wang XF (2017), et al. Experimental research on seismic behaviors of precast concrete columns with large-diameter and high-yield strength reinforcements splicing by grout-filled coupling sleeves. Journal of Civil Engineering(5), pp.27-35.

Zhang XH, Zheng XL and Pan SB, et al (2013). Experiment on Seismic Behavior of Concrete Columns Confined with High-strength Spiral Stirrups. Journal of Architecture and Civil Engineering, 30(2), pp.21-27. 